\title{
Applicability of Electrical Resistivity Tomography Monitoring to Coarse Blocky and Ice-rich Permafrost Landforms
}

\author{
C. Hilbich, ${ }^{1 *}$ L. Marescot,${ }^{2}$ C. Hauck, ${ }^{3}$ M. H. Loke ${ }^{4}$ and R. Mäusbacher ${ }^{1}$ \\ 1 Geographical Institute, University of Jena, Jena, Germany \\ 2 Institute of Geophysics, ETH, Zurich, Switzerland \\ 3 Department of Geosciences, University of Fribourg, Fribourg, Switzerland \\ ${ }^{4}$ Geotomo Software, Gelugor, Penang, Malaysia
}

\begin{abstract}
The inversion and interpretation of electrical resistivity tomography (ERT) data from coarse blocky and ice-rich permafrost sites are challenging due to strong resistivity contrasts and high contact resistances. To assess temporal changes during ERT monitoring (ERTM), corresponding inversion artefacts have to be separated from true subsurface changes. Appraisal techniques serve to analyse an ERTM data set from a rockglacier, including synthetic modelling, the depth of investigation index technique and the so-called resolution matrix approach. The application of these methods led step by step to the identification of unreliable model regions and thus to the improvement in interpretation of temporal resistivity changes. An important result is that resistivity values of model regions with strong resistivity contrasts and highly resistive features are generally of critical reliability, and resistivity changes within or below the ice core of a rockglacier should therefore not be interpreted as a permafrost signal. Conversely, long-term degradation phenomena in terms of warming of massive ground ice at the permafrost table are detectable by ERTM.
\end{abstract}

KEY WORDS: electrical resistivity tomography (ERT); Murtèl rockglacier; depth of investigation (DOI) index; resolution matrix; forward-inverse modelling; permafrost geophysics

\section{INTRODUCTION}

The application of geophysical techniques and in particular of electrical resistivity tomography (ERT) to permafrost-related problems has become a standard approach in recent years and is commonly used for the detection, mapping and characterisation of mountain permafrost (for a review see Kneisel and Hauck, 2008). However, within the context of global warming not only the assessment of its present state but also the

\footnotetext{
* Correspondence to: C. Hilbich, Department of Physical Geography, University of Jena, Loebdergraben 32, Jena 07743, Germany. E-mail: christin.hilbich@uni-jena.de
}

temporal evolution of permafrost are of particular interest. In addition to one-dimensional (1D) thermal monitoring techniques (e.g. in boreholes), 2D ERT monitoring (ERTM) is a promising geophysical method for the observation of possible permafrost degradation. Since measured resistivity is largely controlled by electrolytic conduction of unfrozen water that is distributed across grain boundaries or contained in pores, fractures and faults (e.g. Schön, 2004), ERTM is mainly sensitive to changes in the amount of unfrozen water in the subsurface material. ERTM can therefore provide information on relative changes in ice and water content with time. 
Hauck (2002) and Hilbich et al. (2008) have proven that ERTM can successfully be applied in permafrost conditions, with fine-grained material providing good electrode coupling and relatively low resistivities. Based on results from the Schilthorn monitoring site (Bernese Alps, Switzerland) presented in these studies, ERTM was recently included in the monitoring approach of a number of different permafrost landforms within the Swiss permafrost monitoring network (PERMOS) (Vonder Mühll et al., 2007). This network involves coarse blocky permafrost sites such as rockglaciers or talus slopes that usually constitute a challenging terrain for ERT surveys. Whereas several ERT surveys on permafrost sites with coarse blocky surface characteristics showed good results regarding qualitative analysis of the permafrost conditions (e.g. Marescot et al., 2003; Ikeda and Matsuoka, 2006; Kneisel and Kääb, 2007; Maurer and Hauck, 2007; Hauck and Kneisel, 2008), their potential for quantitative ERTM purposes is still unclear.

Common problems of ERT surveying on coarse blocky material comprise weak (and seasonally variable) electrode coupling to the ground (i.e. the blocks) and bad electrical contact between the individual blocks within the uppermost layer of a rockglacier or talus slope. Dahlin and Loke (1998) have noted that high electrode contact resistances often lead to higher measurement uncertainties. Another problem is the often ice-rich permafrost conditions that cause extremely high resistivities and strong resistivity contrasts between frozen and unfrozen material. In this context, Marescot et al. (2003) have emphasised the high probability of the occurrence of artefacts within the inverted tomograms (provoking misinterpretations) and thus the need for a methodology to evaluate the reliability of inversion results. They have shown that, while the existence and lateral extent of the ice body can be delineated, the resistivity of massive ice cannot be determined accurately. In an attempt to analyse the application of ERT on talus slopes and rockglaciers, they have also indicated that the reliability of information on bedrock underneath massive ice is very limited.

The described uncertainties demonstrate that electrical resistivity measurements in such extreme environments are close to the limit of reliable data acquisition and inversion. In view of these limitations and the anticipated small temporal resistivity changes on annual time scales, ERTM results in coarse blocky permafrost terrain have to be carefully analysed in terms of reliability and possible resolution of the inverted image. In order to extend the usually qualitative application of ERT to quantitative analyses of the resistivity signal, appraisal analysis is an important next step after inversion to evaluate what features in the image are influenced by artefacts due to inversion and what regions are constrained by the data. Appraisal methods aim to evaluate: (a) the confidence we can have in the existence of features observed in the inverted image, (b) the level of detail that can be obtained and (c) the resolution capability at depth (Oldenburg and Li, 1999). Different appraisal methods were presented and discussed by Oldenburg and Li (1999), Alumbaugh and Newman (2000), Friedel (2003), Stummer et al. (2004), and Routh and Miller (2006).

In this paper, we aim to evaluate whether information provided by time-lapse ERT measurements in coarse blocky terrain is reliable enough to assess long-term permafrost degradation. We use different appraisal approaches: calculation of the depth of investigation (DOI) index (introduced by Oldenburg and Li, 1999) and analysis of the resolution matrix in terms of formal model resolutions (e.g. Menke, 1984), and extend their application to repeated ERT surveys with the aim of analysing the possibility of differentiating between the signal (i.e. the temporal resistivity change) and the uncertainties induced by data acquisition (noise), inversion (artefacts) and interpretation. In addition, we apply synthetic modelling to demonstrate the usefulness of the DOI and resolution matrix techniques for the analysis of ERTM data, and to evaluate the internal structure of Murtèl rockglacier (Swiss Alps) that provides an example of coarse blocky surface conditions and massive ice beneath.

We will show that the applied appraisal methods help to identify unreliable model regions, which considerably improve the interpretation of time-lapse data sets, and that ERTM is capable of detecting ground-ice degradation under coarse blocky surface conditions.

\section{APPRAISAL TECHNIQUES FOR ERTM}

\section{Forward and Inverse Modelling of Synthetic Resistivity Models}

The inverse problem in geophysics represents the link of measured data by a mathematical relationship with the specific properties of the earth. In practical ERT applications all inverse problems are underdetermined, which is due to limited data coverage (finite number of electrodes), the resulting limited measurement precision and inevitable noise. This leads to a non-unique solution, meaning that an infinite number of solutions exist that fit the data equally well (Scales and Snieder, 2000; Friedel, 2003). 
The forward problem represents the prediction of a set of geophysical data based on a specific subsurface model and a set of specific model parameters. In ERT surveys, this corresponds to a data set of expected measured apparent resistivities that can be calculated (predicted) from a model of synthetic (i.e. known) specific resistivities.

The inversion of resistivity data can, for example, be carried out using the 2D inversion program RES2DINV (Loke and Barker, 1996; Loke and Dahlin, 2002) that uses a Gauss-Newton algorithm to determine the change in the model parameters:

$$
\left(\mathbf{J}_{\mathbf{k}}^{\mathbf{T}} \mathbf{J}_{\mathbf{k}}+\lambda_{k} \mathbf{F}\right) \Delta \mathbf{m}_{\mathbf{k}}=\mathbf{J}_{\mathbf{k}}^{\mathbf{T}} \mathbf{d}_{\mathbf{k}}-\lambda_{k} \mathbf{F}\left(\mathbf{m}_{\mathbf{k}-\mathbf{1}}-\mathbf{m}_{\mathbf{0}}\right)
$$

with

$$
\mathbf{F}=\alpha_{s} \mathbf{W}_{\mathbf{s}}+\alpha_{x} \mathbf{C}_{\mathbf{x}}^{\mathbf{T}} \mathbf{W}_{\mathbf{x}} \mathbf{C}_{\mathbf{x}}+\alpha_{z} \mathbf{C}_{\mathbf{z}}^{\mathbf{T}} \mathbf{W}_{\mathbf{z}} \mathbf{C}_{\mathbf{z}}
$$

where $\Delta \mathbf{m}_{\mathbf{k}}$ is the change in model parameters for the iteration $\mathrm{k}, \mathbf{m}_{\mathbf{k}-\mathbf{1}}$ is the model parameter vector (the logarithms of the model resistivity values) at the iteration $\mathrm{k}-1, \mathbf{m}_{\mathbf{0}}$ is a homogeneous half-space reference model, and $\mathbf{d}_{\mathbf{k}}$ is the discrepancy vector, the difference between the logarithms of measured and calculated apparent resistivity values. $\mathbf{W}_{\mathbf{x}}, \mathbf{W}_{\mathbf{z}}$ and $\mathbf{W}_{\mathbf{s}}$ and $\mathbf{C}_{\mathbf{x}}$ and $\mathbf{C}_{\mathbf{z}}$ are weighting and smoothing matrices, respectively, and the damping factor $\lambda_{k}$ determines the relative importance given to minimising the model roughness. $\alpha_{\mathrm{x}}$ and $\alpha_{\mathrm{z}}$ are the relative weights (which are both normally set to 1.0) for the roughness filters in horizontal and vertical directions. $\alpha_{s}$ is the relative weight (usually set to a smaller value such as 0.01 to 0.05 ) for the damping factor that minimises deviation of the model resistivity from a reference model (see Loke and Dahlin, 2002; Oldenburg and Li, 1999). $\mathbf{J}_{\mathbf{k}}$ is the Jacobian matrix of partial derivatives (sensitivity), which is entirely recalculated after each iteration. For ERTM data sets, a joint inversion technique can be carried out in RES2DINV, which is based on crossmodel constraints that use the model obtained from the so-called time-lapse inversion of an initial data set as a reference model to constrain inversion of the later time-lapse data sets (Loke, 1999).

In contrast to the inverse problem, solution of the forward problem is unique. Forward modelling of a synthetic resistivity model thus allows us to investigate the response of the inversion process to a given subsurface structure to evaluate the possible resolution of features of interest, the DOI, or the occurrence of inversion artefacts. As ERT data with high resistivities and/or high resistivity contrasts are known to favour the development of inversion artefacts (e.g. Rings et al., 2008), forward/inverse modelling is particularly important for ERT surveys on permafrost. For ERTM purposes, it is further useful to investigate the response of the inverted model to the expected time-dependent variations of specific resistivities and its resolution potential. By this, interpretation methods can be tested under controlled circumstances to overcome the problem of only limited in-situ control (e.g. only by $1 \mathrm{D}$ boreholes) of the subsurface structures in a natural environment (Dahlin and Loke, 1998; Olayinka and Yaramanci, 2000; Hauck and Vonder Mühll, 2003; Fortier et al., 2008).

Figure 1 illustrates the concept of forward/inverse modelling for an example from Murtèl rockglacier (which will be introduced in the following section). Based on the results of a real ERT data set obtained in August 2006 at Murtèl rockglacier (Figure 1a and b) and the information from a borehole, we generated a synthetic model (Figure 1c) consisting of: (1) an unfrozen coarse blocky active layer $(20 \mathrm{k} \Omega \mathrm{m})$, (2) an unfrozen fine-grained rockglacier front $(10 \mathrm{k} \Omega \mathrm{m}),(3)$ a highly resistive ice core $(2000 \mathrm{k} \Omega \mathrm{m})$ segmented by (4) a less resistive anomaly $(200 \mathrm{k} \Omega \mathrm{m})$, (5) an underlying layer of unfrozen blocks and debris $(20 \mathrm{k} \Omega \mathrm{m})$ possibly including a talik (according to Vonder Mühll and Holub, 1992), and (6) frozen coarse blocks or bedrock $(200 \mathrm{k} \Omega \mathrm{m})$. The simulated data set of expected apparent resistivities was calculated for the same electrode configuration as applied for collecting the real data (Wenner array, 48 electrodes, 5-m spacing), using the software RES2DMOD (Loke, 2002). To approximate field conditions, Gaussian random noise (Press et al., 1992) of 5 per cent was added to the simulated data, which were then inverted with the robust inversion scheme of the software RES2DINV (Loke et al., 2003). The iterative inversion procedure was stopped as soon as the absolute data misfit value fell below the noise level. The inverted synthetic model (Figure 1d) is compared to the inversion of the real data (Figure 1b), and, if necessary, the synthetic model is adapted and the forward-inverse cycle repeated until both synthetic and real data inversion produce similar results. According to this back-and-forth procedure (described by Fortier et al., 2008), we developed the synthetic model shown in Figure 1c and d that can be regarded as a possible representation of the subsurface of Murtèl rockglacier.

\section{DOI}

The DOI index technique was introduced by Oldenburg and Li (1999) and first used by Marescot et al. 

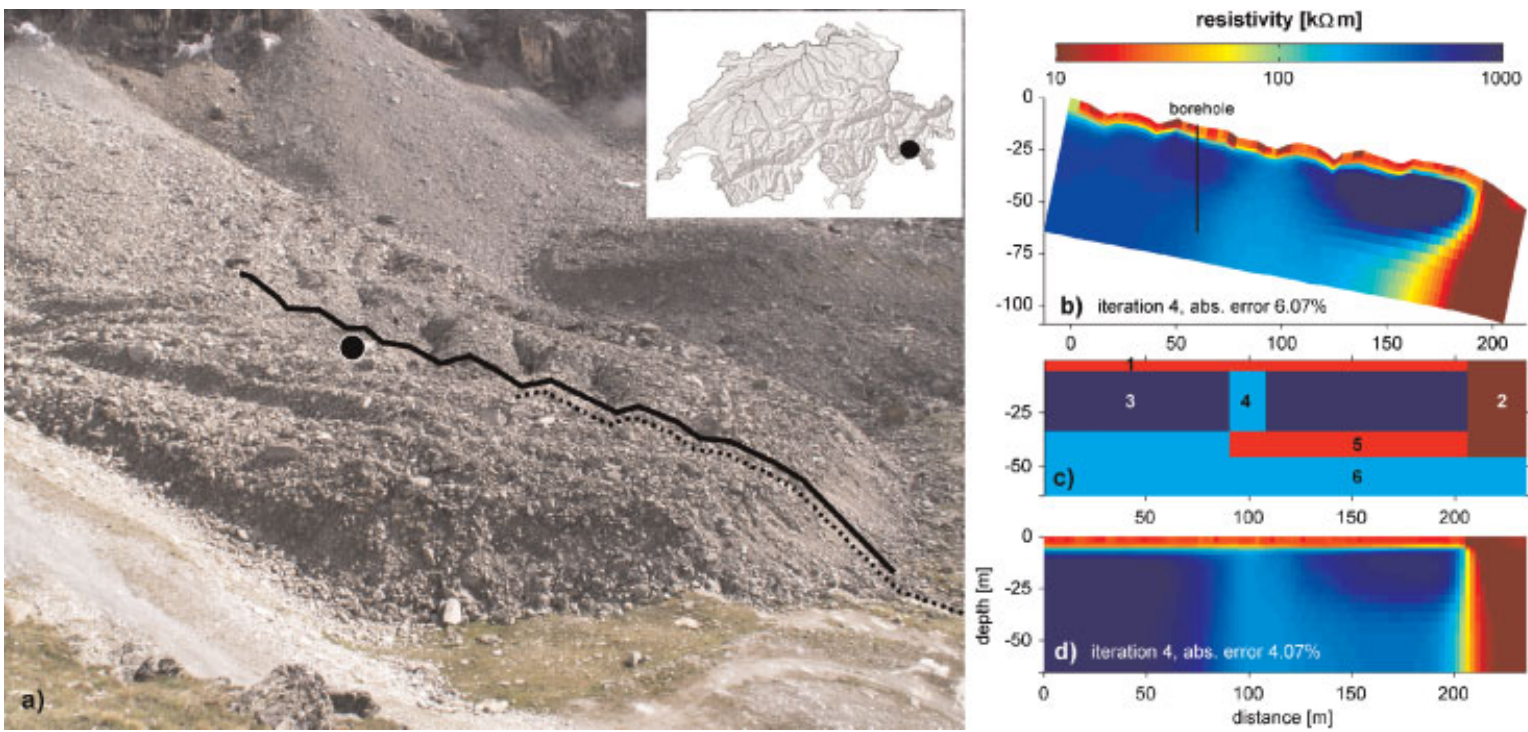

Figure 1 (a) Photograph of Murtèl rockglacier with position of the borehole (dot), the electrical resistivity tomography (ERT) monitoring line (bold) and the ERT line of 1998 (dashed), (b) inverted image of an ERT measurement in August 2006, and possible representation of the real data set in terms of (c) a synthetic model and (d) the corresponding inversion result. Numbers in (c) indicate the various elements of the model and are described in the text. The location of the site within Switzerland is indicated in the inset.

(2003) for permafrost studies. In this appraisal technique, two inversions of the same data sets are carried out using Equation (1), but with two different reference models with homogeneous resistivity values $\mathbf{m}_{\mathbf{0 1}}$ and $\mathbf{m}_{\mathbf{0 2}}$. In practice, the DOI index is normalised using the DOI value at the bottom of the model DOI $_{\text {bottom, }}$, and is defined by:

$$
\operatorname{DOI}(\mathbf{x}, \mathbf{z})=\frac{\mathbf{m}_{1}(\mathbf{x}, \mathbf{z})-\mathbf{m}_{\mathbf{2}}(\mathbf{x}, \mathbf{z})}{\mathbf{D O I}_{\text {bottom }}\left(\mathbf{m}_{\mathbf{0 1}}-\mathbf{m}_{\mathbf{0 2}}\right)}
$$

where $\mathbf{m}_{\mathbf{1}}$ and $\mathbf{m}_{\mathbf{2}}$ are resistivity values of the same particular cell for the two inversion results. The DOI value will be close to 0 in regions of the models well constrained by the data since the two inversions produce the same results. Conversely, the DOI will approach unity in regions of the model where the inversion result is controlled only by the reference models and the data have negligible influence.

In this paper, the two reference models used are one tenth and ten times the average of the observed apparent resistivity of the data sets. The depth range of the models was extended to five times the median DOI of the largest array spacing used (Edwards, 1977), so that the resistivity of the deepest model cells in the inversion model will be close to the reference model used. Moreover, a high damping factor of $\alpha_{\mathrm{s}}=0.05$
(Equation 2) was used, thus giving a large impact to the reference model used.

The technique is illustrated for Murtèl rockglacier (Figure 2). The average observed apparent resistivities $\left(\mathbf{m}_{\mathbf{0}}\right)$ of the exemplary data set is $86.7 \mathrm{k} \Omega \mathrm{m}$, the two inversions of the synthetic data set were thus carried out using two reference models with resistivities of $\mathbf{m}_{\mathbf{1}}=8.67 \mathrm{k} \Omega \mathrm{m}$ and $\mathbf{m}_{\mathbf{2}}=867 \mathrm{k} \Omega \mathrm{m}$ (Figure $2 \mathrm{a}$ and $\mathrm{b}$ ). The DOI index is then calculated using Equation (3) (Figure 2c). The two inversions produce similar models close to the surface (DOI close to 0), where the data have a superior influence, but only reflect the reference model at depth $(\mathrm{DOI} \sim 1)$. When a cut-off value of the DOI index (e.g. $>0.2$, as suggested by Oldenburg and $\mathrm{Li}, 1999$ ) is used to disregard unreliable model regions, the two inversion results depict very similar images (Figure $2 \mathrm{~d}$ and e). Using the DOI index technique, unreliable resistivity zones, which are not constrained by the data, can be identified and the misinterpretation of inversion artefacts can be avoided. The resulting resistivity image is very similar to the synthetic model presented in Figure 1 in the zones where the DOI index is lower than 0.2.

Figure 3 shows the vertical resistivity distribution for the two inversions along the black lines drawn in Figure $2 \mathrm{a}$ and $\mathrm{b}$ at horizontal distances of 90 and $140 \mathrm{~m}$. Close to the surface at depths less than $5 \mathrm{~m}$, both inversions produce similar results, confirming 


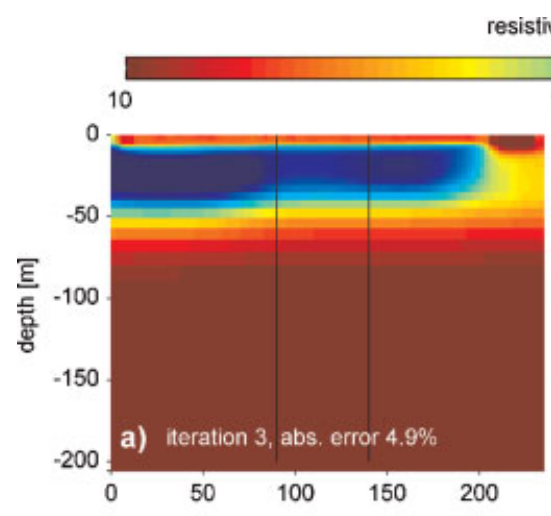

sistivity [k $\Omega \mathrm{m}]$
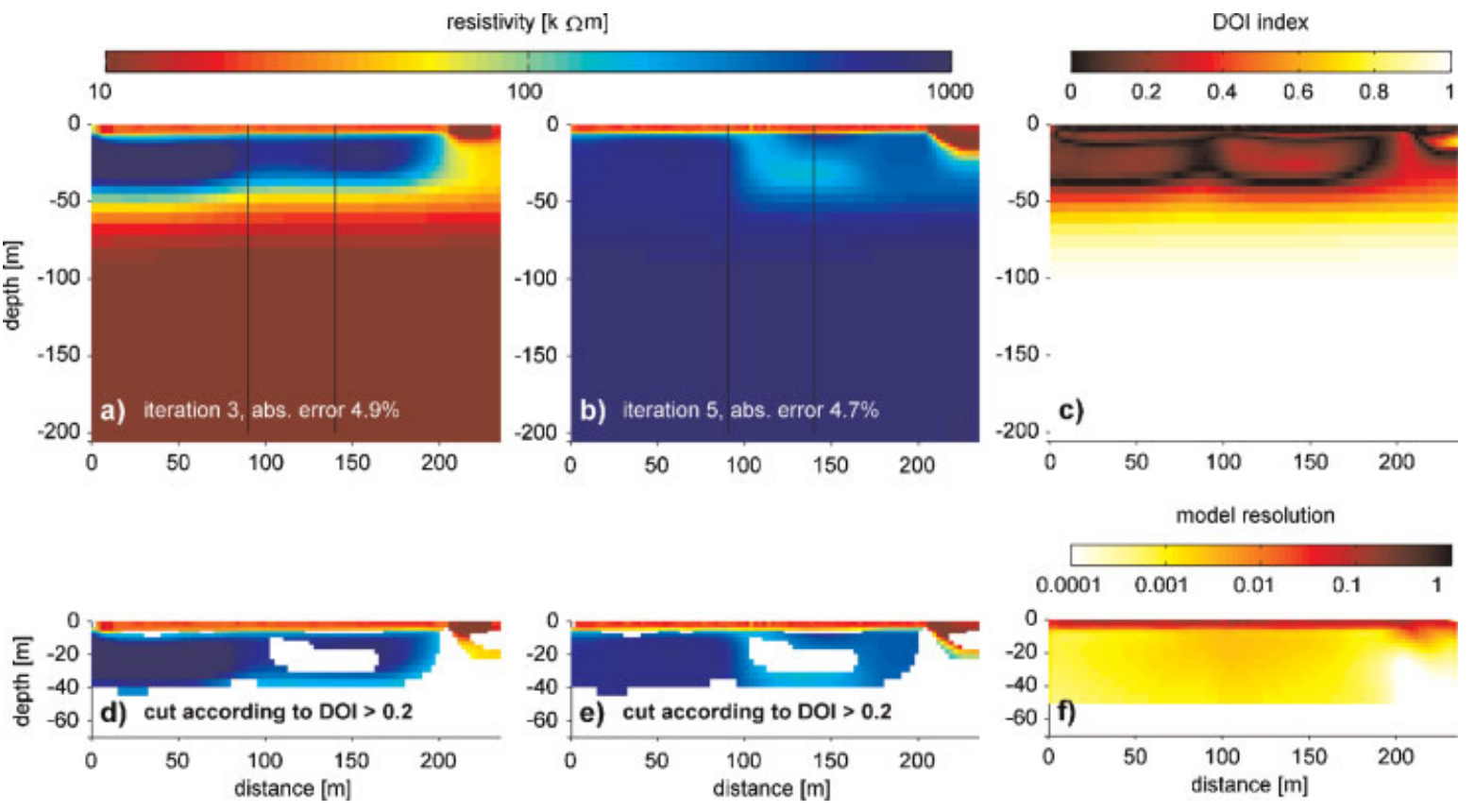

Figure 2 Illustration of the two inversion results of the synthetic Murtèl rockglacier model based on different reference models with factors (a) 0.1 and (b) 10 of average apparent resistivity, and (c) the calculated depth of investigation (DOI) index. The inverted resistivity models (a) and (b) were cut according to a DOI index $>0.2$ in (d) and (e). Formal model resolution of the synthetic rockglacier model is shown in (f).

that the active layer is reasonably well resolved. In this region, the DOI index is close to 0 . In the middle of the resistive body (between 20 and $30 \mathrm{~m}$ in depth), the two inversions produce still similar results at $90 \mathrm{~m}$, but very different results at $140 \mathrm{~m}$, thus showing that no reliable information can be obtained for electrical properties of the highly resistive ice body, whereas in a zone with lower resistivities (at $90 \mathrm{~m}$ ) the reliability is much higher. Below, the resistivities approach the values of the reference models used, and thus will cross at a certain point, resulting in a DOI index of 0 , although this does not mean that that part of the model is reliable. This clearly shows that DOI patterns should not be interpreted as such, but have to be used as a guideline to highlight regions of the model that are not very well constrained by the data. We therefore avoid the choice of an arbitrary cut-off value and use the DOI index to scale the intensity of the colours of the inversion results in this study.

\section{The Model Resolution Matrix}

As a further appraisal technique, the resolution matrix technique identifies model regions where the model parameters (e.g. the specific resistivities) can be independently resolved. Following Menke (1984), the model resolution can be expressed as:

$$
\mathbf{m}^{\text {est }}=\mathbf{R} \mathbf{m}^{\text {true }}
$$

where $\mathbf{R}$ is the model resolution matrix. If $\mathbf{R}$ equals the identity matrix $\mathbf{I}\left(\mathbf{m}^{\text {est }}=\mathbf{m}^{\text {true }}\right)$, each model parameter is uniquely determined and its resolution equals 1 . Conversely, when $\mathbf{R}$ is not an identity matrix, estimates of the model parameters are then weighted averages of the true model parameters and their resolution is $<1$. The resolution matrix for iteration $\mathrm{k}$ is computed using Equation (1), but with no reference model included:

$$
\mathbf{R}_{\mathbf{k}}=\left(\mathbf{J}_{\mathbf{k}}^{\mathbf{T}} \mathbf{J}_{\mathbf{k}}+\lambda_{k} \mathbf{F}\right)^{-1} \mathbf{J}_{\mathbf{k}}^{\mathbf{T}} \mathbf{J}_{\mathbf{k}}
$$

This relation is strictly valid only for linear problems. As electrical inversion is non-linear, the resolution matrix in this case is only an approximation. Figure $2 \mathrm{f}$ shows an example of a resolution matrix used for the Murtèl synthetic example. We observe high resolution in the active layer and low resolution in the ice core at greater depths.

The information we get from $\mathbf{R}$ and $\mathbf{D O I}$ is slightly different and thus the techniques are employed in a 

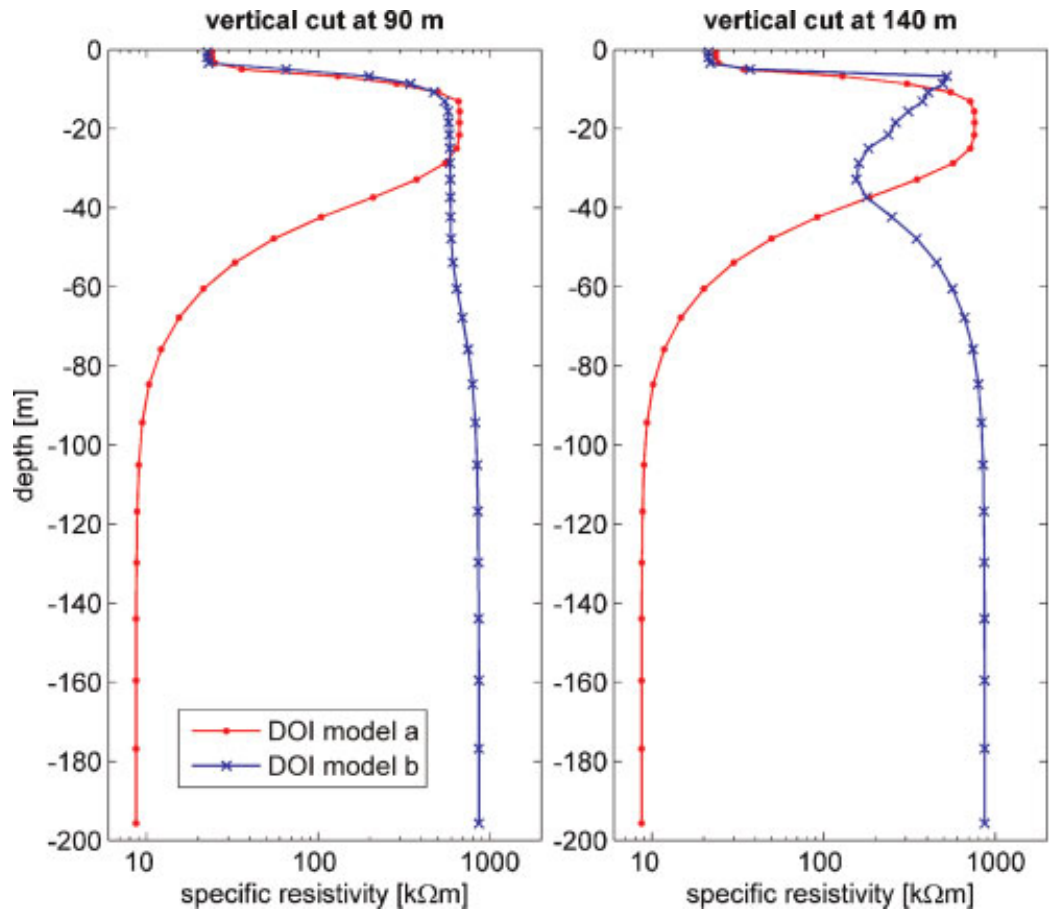

Figure 3 A vertical cut through depth of investigation (DOI) models (a) and (b) in Figure 2 at 90- and 140-m horizontal distance. This figure is available in colour online at www.interscience.wiley.com/journal/ppp.

complementary fashion in this study to assess the reliability of the inversion images.

\section{FIELD SITE}

Murtèl rockglacier is located near Piz Corvatsch on the northern slope of the Upper Engadine valley (eastern Swiss Alps). It is one of the most intensely investigated rockglaciers worldwide. Borehole temperatures, recorded since 1987 (Haeberli et al., 1998; Hoelzle et al., 2002; Vonder Mühll et al., 2007), provide the longest temperature record in Alpine permafrost. Apart from borehole observations (Vonder Mühll and Holub, 1992; Arenson et al., 2002), no direct information exists of the interior structure of the rockglacier. Indirect information however, has been inferred from geophysical surveys (Vonder Mühll and Klingelé, 1994; Vonder Mühll et al., 2000; Hauck and Vonder Mühll, 2003; Maurer and Hauck, 2007).

The stratigraphy revealed by drilling (Haeberli et al., 1988; Vonder Mühll and Holub, 1992) comprises: (1) a ca. 3-m thick active layer (consisting of large blocks and debris), (2) a zone with massive ice between 3- and 15-m depth (ice content ca. 80-90\%;
Arenson and Springman, 2005), and (3) a layer with ice and frozen sand between 15- and 30-m depth (ice content 30-35\%). (4) A layer with boulders (low ice content) underneath is followed by (5) probable bedrock at about $52 \mathrm{~m}$ in depth. The geophysical surveys on the rockglacier revealed that this vertical structure is basically homogeneous in a lateral direction (Hauck et al., 2003; Maurer and Hauck, 2007).

Creep rates derived from photogrammetry are relatively slow with surface velocities between 5 and $15 \mathrm{~cm}$ per year (Kääb et al., 1998). Many rockglaciers in the Alps have experienced pronounced acceleration in recent years (Roer et al., 2005; Kääb et al., 2007; Delaloye et al., 2008), and Murtèl also shows a small increase in horizontal velocity, but the rates range between a few centimetres to decimetres per year and are much lower than for most other accelerating rockglaciers (I. Roer, personal communication, 2008).

Due to its relatively inert condition the expected response of the rockglacier to climate change appears to be limited, and no distinct degradation phenomena were observed up to now. However, the ERTM results presented in this study hint at a more heterogeneous internal structure and temporal changes than previously assumed. 


\section{DATA ACQUISITION}

A 235-m long fixed electrode array (48 electrodes, 5$\mathrm{m}$ spacing) was installed in a longitudinal direction across the lower part and front of the rockglacier in summer 2005 (Figure 1a). The array was installed in the vicinity of a 145-m long ERT survey (dashed line in Figure 1a) conducted in July 1998 (Hauck et al., 2003). Electrode coupling was extremely difficult in the blocky surface layer and considerable efforts were undertaken to fix the electrodes as deep and as firmly as possible in the blocky ground. In critical cases, significant improvement was achieved by parallel coupling of two electrodes (partly screwed into blocks), which finally allowed sufficient electric contact to the ground in summer (when it is not too dry). We used a Syscal system (Iris Instruments) with high internal impedance to collect the data. Experiences on different rockglaciers showed that contact resistances can sometimes be as high as $500 \mathrm{k} \Omega$ and more, only allowing input currents predominantly $<2 \mathrm{~mA}$, and often as low as $0.03 \mathrm{~mA}$, but still yielding good results. As one aim of the study was to evaluate the feasibility of ERTM for automated data acquisition in the near future, we avoided wetting the electrodes in this case, although contact resistances can be reduced by this technique.

A Wenner array was used for all the ERT measurements presented. Following stacking operations on the measured voltage-to-current ratio to evaluate measurement standard deviation, data with standard deviations greater than 10 per cent were discarded. Under less demanding permafrost conditions (i.e. fine-grained material and good electrode coupling), variations usually remain around 0 and exceed 5 per cent in only a few cases. On coarse blocky landforms similar values are achieved under favourable conditions, but with a larger number of outliers that must be deleted. In general, a full measurement data set is considered successful, when less than 10 per cent of the data have to be deleted. From the ERTM measurements made at Murtèl rockglacier, three data sets are of high quality, with only 2 to 7 per cent of the data deleted: 17 August 2006, 30 August 2007 and 9 September 2008. Another data set from 9 July 2007, which is of lower quality, is also presented here (15\% deleted). Although the original intention was a long-term comparison with the ERT survey from July 1998 (Hauck et al., 2003), this profile has even worse overall data quality ( $23 \%$ deleted) and was therefore not included in this analysis.

In winter, when the active layer is frozen, electric contact becomes extremely weak and contact resist- ances rise to $>2000 \mathrm{k} \Omega$, resulting in input currents $<$ $0.02 \mathrm{~mA}$. Data quality decreases substantially with many outliers with a standard deviation $>10$ per cent. As no satisfactory measurements have been obtained during the winters to date, only ERTM results from July to September are presented here.

\section{RESULTS}

\section{Forward-inverse Modelling}

Prior to the analysis of field data, a synthetic rockglacier model was used to evaluate the resolution potential of ERTM in relation to different scenarios and the accuracy of time-dependent resistivity changes in different model regions. The synthetic model in Figure 1c was simplified (Figure 4a, upper panel) and is referred to as the initial model (IM) in the following. It was then altered within the uppermost $10 \mathrm{~m}$ to resemble idealised freezing and thawing scenarios in the active layer and at the top of the ice core (Figure 4a).

\section{Analysis of Individual Inversion Results.}

The first three scenarios in Figure 4a illustrate resistivity changes within the active layer: (1) frozen $(50 \mathrm{k} \Omega \mathrm{m})$ and $(2)$ unfrozen moist conditions $(2 \mathrm{k} \Omega \mathrm{m})$, and (3) a scenario identical to the IM $(20 \mathrm{k} \Omega \mathrm{m})$ but with an extremely low resistive (saturated) layer $(0.2 \mathrm{k} \Omega \mathrm{m})$ at the bottom of the active layer. Scenario (3) represents an idealised case of rapid water infiltration through the active layer but delayed runoff on the impermeable ice core during the snow melt season. In scenario (4), the resistivities are identical to the IM, but the thickness of the active layer is increased by $1 \mathrm{~m}$ at the expense of the uppermost part of the ice core. In scenarios (5) and (6), the IM was locally modified to illustrate potential causes of local anomalies in the inversion result (motivated by observed low resistive anomalies at Murtèl rockglacier that will be discussed later): (5) a situation similar to scenario (3) but with a locally confined low resistive layer $(2 \mathrm{k} \Omega \mathrm{m})$, and (6) a restricted version of scenario (4) with only local active-layer thickening at the expense of the thickness of the ice core.

Figure $4 \mathrm{~b}$ shows inversion results of the different scenarios. In general, the inverted resistivities of the active layer largely satisfy the preset values, while larger deviations from the preset values are found at the right boundary of the model (corresponding to the rockglacier front) and at greater depths (comprising both ice core and bedrock). Note that the synthetic 

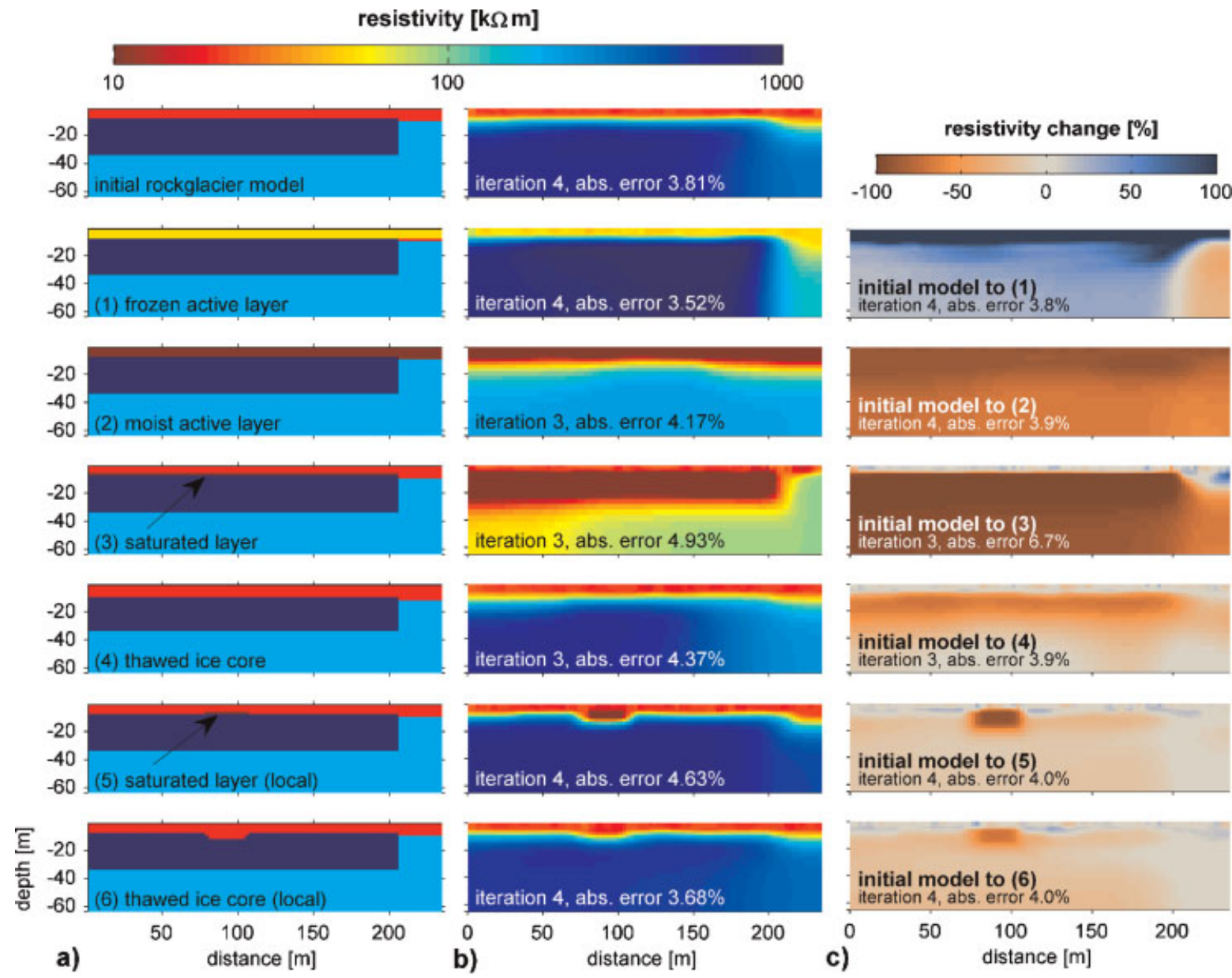

Figure 4 The initial rockglacier model (upper panel) and different freezing and thawing scenarios: (a) synthetic resistivity models, (b) inverted synthetic resistivity models and (c) percentage change in resistivities relative to the initial model revealed by time-lapse inversion.

resistivities of the ice core and bedrock remained unchanged in all scenarios, so that all deviations in the inverted resistivities of the frontal part, the ice core, and the bedrock layer from the IM are a consequence of resistivity changes within the active layer.

The inversion results of scenarios (2) and (3), characterised by low active-layer resistivities, constitute major exceptions from the general model responses. Even though the inverted resistivities of the ice core are greatly underestimated in all inverted models, inversion responses of scenarios (2) and (3) do not indicate the presence of the ice core. In case (2), the resistivity of the active layer is so low that almost no current flows through deeper model regions. The saturated layer in case (3) is extremely narrow (ca. $1 \mathrm{~m})$, and causes the emergence of an inversion artefact (ca. 25-m thick low resistive layer). According to Dahlin and Loke (1998), calculation errors usually increase with both resistivity contrast and decreasing thickness of the low resistive layer, which may explain the extreme response of inversion. The inverted resistivities at greater depth in both models do not represent the data but are greatly influenced by the resistivity of the starting models (by default the average apparent resistivity in RES2DINV), which are much lower than for the other scenarios (Table 1).

Clear detection of the lower boundary of the ice core is not evident in the different synthetic models. The limited ability to resolve stratigraphic information below the transition zone to the ice core is due to very limited resolution capacity of the Wenner configuration at depth (e.g. Stummer et al., 2004) and also to the concentration of current flow within the least resistive upper layer. This is supported by the more 
Table 1 Absolute model misfits $\left(1 / \mathrm{N} \Sigma_{k}\left(\left|m_{k+1}-m_{k}\right| /\left|m_{k}\right|\right)\right)$ (according to Equation 1) within the upper $40 \mathrm{~m}$, and average apparent resistivities of the initial rockglacier model and the different freezing and thawing scenarios.

\begin{tabular}{lccccccc}
\hline Model & Initial & $\begin{array}{c}(1) \\
\text { Frozen active } \\
\text { layer }\end{array}$ & $\begin{array}{c}(2) \\
\text { Moist active } \\
\text { layer }\end{array}$ & $\begin{array}{c}(3) \\
\text { Saturated } \\
\text { layer }\end{array}$ & $\begin{array}{c}(4) \\
\text { Thawed } \\
\text { ice core }\end{array}$ & $\begin{array}{c}(5) \\
\text { Saturated } \\
\text { layer (local) }\end{array}$ & $\begin{array}{c}\text { Thawed ice } \\
\text { core (local) }\end{array}$ \\
\hline $\begin{array}{l}\text { Absolute model misfit } \\
\begin{array}{l}\text { Average } \rho_{\mathrm{a}} \\
\text { (starting model) }\end{array}\end{array}$ & $0.25 \%$ & $0.24 \%$ & $0.29 \%$ & $1.46 \%$ & $0.23 \%$ & $0.29 \%$ & $0.25 \%$ \\
\hline
\end{tabular}

detailed synthetic model of Murtèl rockglacier shown in Figure 1c, where a vertical intersection of the ice core was introduced to account for the higher complexity in the interior of the rockglacier (Figure 1b). The continuous vertical zone of significantly lower resistivities $(200 \mathrm{k} \Omega \mathrm{m})$ enabled current flow around the right part of the ice core, and realistically reproduced the resistivity pattern of the observed ERT data (cf. Figure 1c and d). Conversely, the results from a synthetic model without this vertical layer (not shown) were less consistent with the observed data. As a consequence of this 'channelled' current flow, the lower boundary of the ice-rich layer can be identified only in the right-hand part of Murtèl rockglacier (Figure 1d). The capacity of ERT to delineate the thickness of such ice-rich layers can be increased further by extending the survey line into unfrozen regions at both ends of a rockglacier to enable current flow below the highly resistive core (see also results by Hauck et al., 2003, for an ice-cored moraine).

A vertical cut through the synthetic and inverted synthetic models at 90-m horizontal distance is shown in Figure 5. The difference between the sharp resistivity contrasts of the synthetic models and the smooth contrasts of the inversion models, caused by the least-squares approach of the algorithm, is clearly shown. Apart from this, the inverted resistivities of scenarios (1), (4) and (6) largely correspond to their synthetic models in the upper part of the profile. In all scenarios, the thickness of the active layer, defined as the depth where resistivity sharply increases, is relatively well resolved, despite the large electrode spacing, but the resistivity of the ice core is underestimated (cf. Figure 5). In contrast, the resistivity of the very low resistive layers in scenarios (3) and (5) is overestimated and they completely fail to resolve the thickness of the low resistive layer. Sharp
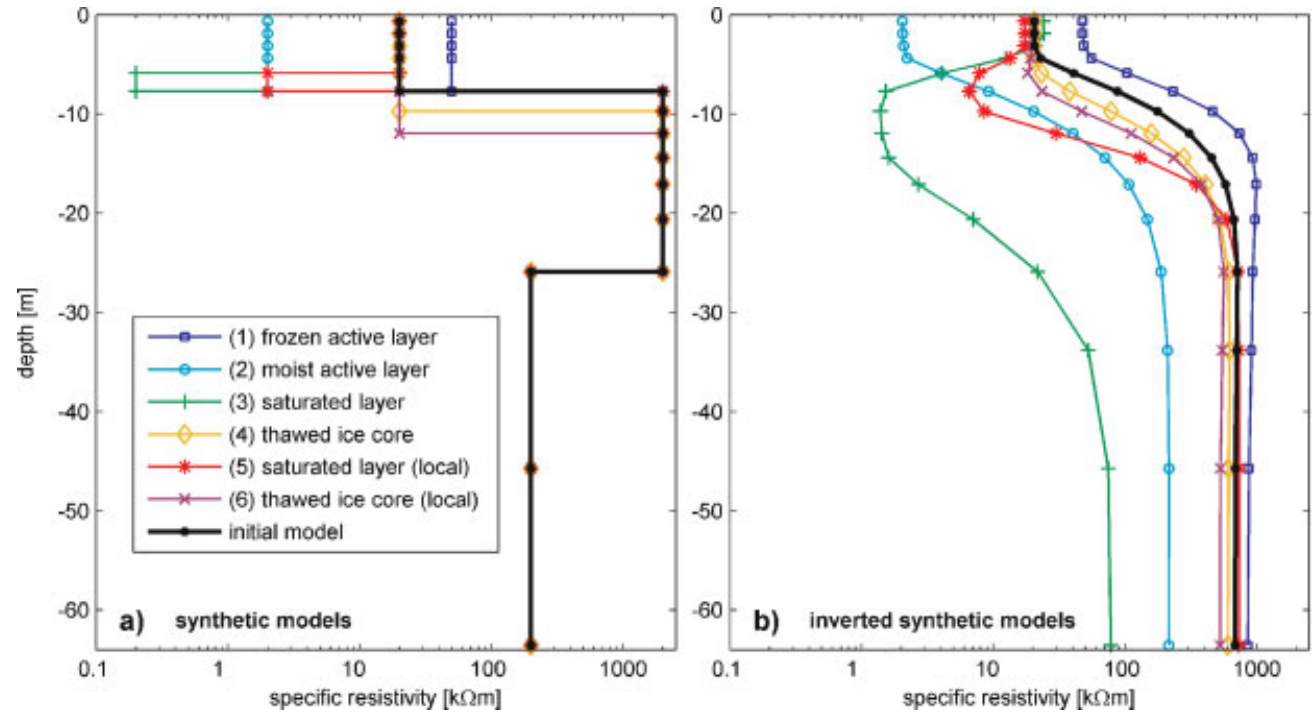

Figure 5 Resistivity-depth plots representing a cut through (a) the synthetic and (b) the inverted synthetic rockglacier models in Figure 4a and $\mathrm{b}$ at $90-\mathrm{m}$ horizontal distance. This figure is available in colour online at www.interscience.wiley.com/journal/ppp. 
boundaries between stratigraphic interfaces of the synthetic models generally appear gradational, which is a consequence of the imposed damping and smoothness constraints and hence a common characteristic of tomographic inversion results (Stummer et al., 2004).

However, Figure 5 also indicates that, within moderate bounds, relative differences between the synthetic models are properly resolved by inversion, as is the case for scenarios (1), (4) and (6), which are characterised by the lowest model misfits in Table 1 . Temporal resistivity changes due to freezing/thawing of the active layer or melting of the top of the ice core should therefore be detectable by ERTM. Further synthetic modelling tests (not shown here) revealed that thawing of the ice core from below would not be detectable under the given circumstances.

Another important result of synthetic modelling is that the large differences in the inverted models are a consequence of the different starting models and the limited resolution at depth. Absolute resistivity values of the ice core are very likely a function of the resistivity of the active layer, and hence the resistivity contrast. In ERT applications that aim to relate absolute resistivity values of highly resistive ice bodies to, for example, possible origins of ice in rockglaciers (e.g. Haeberli and Vonder Mühll, 1996; Ishikawa et al., 2001), ice content, or subsurface temperatures, the effect of strong resistivity contrasts must be taken into account. Concerning ERTM, resistivity changes in the ice core are therefore not reliably interpretable if temporal resistivity changes within the active layer also occur.

\section{Analysis of Time-lapse Inversion Results.}

Time-lapse inversion was performed for all scenarios (with the inversion results of the IM used as reference model) to analyse the accuracy of modelled resistivity changes relative to the IM (Figure 4c). Since the reliability of results for scenarios (2) and (3) is low (see above), we address only resistivity changes from the IM to the other four scenarios.

Freezing of the active layer causes a resistivity increase of more than 100 per cent in the upper part of the time-lapse tomogram in scenario (1) (Figure 4c: IM to (1)). At greater depths pronounced resistivity increases of up to 50 per cent, and even 100 per cent close to the transition to the front, are also present. As the reduction of resistivity contrast (by the frozen active layer) improves resolution of the true resistivity of the ice core (cf. Figure 5), the observed temporal resistivity increase reflects only the different resolution capacities of the two scenarios, and not a change in true resistivity. This is also supported by the lowest data misfit value of all time-lapse inversions revealed for the frozen active-layer scenario.

Scenario (4) (Figure 4c: IM to (4)) strikingly illustrates the capability of ERTM to detect melting of massive ground ice from above, while resistivity in the active layer remains unchanged. However, the reduction in ice-core thickness is greatly overestimated (5-10 m instead of $1 \mathrm{~m})$ ! This is partly due to a decrease in resolution of the electrical method with depth, but a major factor is the limited vertical resolution (5-m electrode spacing), resulting in an increased thickness of the zone with changed resistivity in the time-lapse tomogram. As a consequence of the principle of equivalence, the overall resistivity decrease obtained (about $60-70 \%$ ) is lower than in the synthetic model (99\%). As in scenario (1), the resistivity decrease below the melted ice core is very likely associated with the different resolution capacities of the two models at depth.

Time-lapse responses of scenarios (5) and (6) (Figure 4c: IM to (5) and IM to (6)) are similar, but their causes differ significantly. Although the introduced anomaly in scenario (5) is smaller in size than in scenario (6), its response in the time-lapse inversion is larger. As discussed earlier, the presence of a layer with low resistivity at the transition to a highly resistive layer (5) causes an inversion artefact, suggesting a 'block' with decreased resistivity within rather than a thin layer with low resistivity on the ice core. Interestingly, the locally restricted scenario of ice core melting (6) provides a more realistic estimate of its depth extent than scenario (4), though still overestimated by a factor of 6 to 7 .

Even though the overall trends are well reproduced in all cases, it can be stated that the interpretation of time-lapse tomograms of rockglaciers is generally difficult due to the high probability of contamination with inversion artefacts. Moreover, one should be aware of sometimes misleading resistivity changes as a consequence of limited resolution power. Nevertheless, the analyses show that freezing or thawing of the active layer as well as degradation (shrinking) of the ice core are certainly detectable by ERTM, whereas accuracy in the estimation of both spatial dimension and values may be limited in some cases.

\section{ERTM Results}

After analysis of the general applicability of ERTM to the observation of permafrost evolution, ERTM data from Murtèl rockglacier from August 2006, July 2007, August 2007 and September 2008 are examined in the following. The synthetic modelling tests indicate 

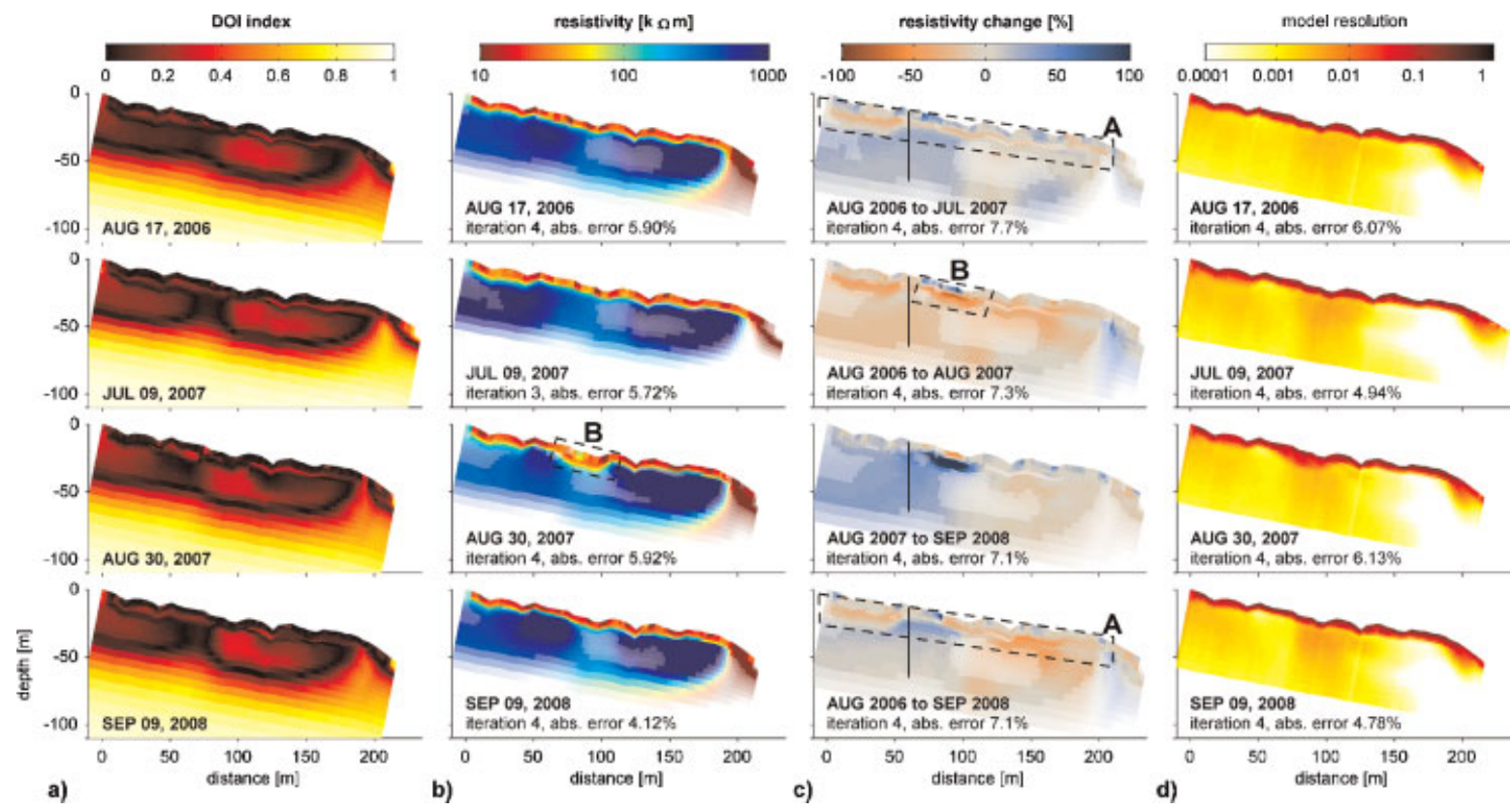

Figure 6 (a) Calculated depth of investigation (DOI) index, (b) inverted models with intensity of colours scaled by the DOI index (for better visibility scaled by DOI index $>0.2$ ), (c) time-lapse tomograms scaled by DOI $\max >0.2$ and (d) formal model resolution for the Murtèl data set. Pale colours in (b) and (c) are associated with unreliable inversion results. Highlighted zones A and B are described in the text.

relatively low reliability for the resistivity values below the active layer as a consequence of the extremely resistive ice core. The DOI index technique and the resolution matrix approach are applied to appraise further reliability of the spatial resistivity distribution and temporal changes.

\section{Analysis of the DOI Index.}

Figure $6 \mathrm{a}$ and $\mathrm{b}$ shows the calculated DOI index and the inversion results from the four measurement dates, with intensity of the colours scaled by DOI values $>$ 0.2 (pale colours are associated with a high DOI index and thus denote unreliable inversion results). At first glance the tomograms do not differ much. Striking features are the comparatively low resistivity of the active layer (ca. $20 \mathrm{k} \Omega \mathrm{m}$ ), the highly resistive ice core $(>1000 \mathrm{k} \Omega \mathrm{m})$ and a zone in the central part of the ice core with intermediate resistivities (ca. 300$500 \mathrm{k} \Omega \mathrm{m}$ ). On closer inspection, resistivity of the ice core (especially the left-hand part) changes considerably between the subsequent measurement dates (by up to $500 \mathrm{k} \Omega \mathrm{m}$ ). Moreover, the thickness of the active layer exhibits a pronounced variability in the central part (especially in August 2007). Bedrock beneath the rockglacier (expected at about 50-m depth) is not resolved in all tomograms. Relatively small data misfit values (referred to as absolute errors in the figures) in all cases confirm the good overall quality of these inversion results.

The calculated DOI indices (Figure 6a) vary slightly between the measurement dates, but a common pattern can be identified in all tomograms: DOI values remain very low $(<0.2)$ in the active layer, show several intermediate zones $(0.2-0.4)$ in the region of the ice core and the front of the rockglacier, and increase rapidly at a depth of about $50 \mathrm{~m}$, indicated by complete fade out of the colours in Figure $6 \mathrm{~b}$.

Notwithstanding the original sense of the DOI concept to define the depth region where the image is no longer constrained by the data, the method is also sensitive to zones with distinct resistivity gradients, as the strength of the resistivity gradient significantly depends on the reference model used. This is the case for the transition between the active layer and ice core, between the ice core and the rockglacier front, and within the vertical anomaly (between 80 - and $120-\mathrm{m}$ horizontal distance) in the neighbourhood of the most resistive zone of the profile. Especially around these transition zones the DOI index can be a valuable measure of how well gradational transitions reflect the subsurface conditions.

Apart from the transition zones, the DOI index clearly indicates low sensitivity within the ice core, especially in the left-hand part, which corresponds to 
the above-mentioned zone with strong (but unexpected) resistivity changes between subsequent measurements. The DOI values in the upper 10 $20 \mathrm{~m}$ of the ice core are below 0.2 , suggesting that this is the part of the ice core which is best constrained by the data. Interestingly, the vertical zone intersecting the ice core is assessed as having low reliability in all data sets. However, the forward modelling tests revealed that a vertical anomaly with comparatively low resistivity is a necessary condition to reproduce the measured data (see also Figure 1c and d), and that the resistivity of this zone was overestimated by a factor of $>2$ in most inversion results. As discussed earlier, current flow is basically restricted to the active layer and front of the rockglacier, and, by the presence of this vertical anomaly, around the frontal part of the ice core. The different reference models used for calculation of the DOI significantly influence resistivity of this zone, causing high DOI values. Consequently, the presence of a less resistive zone within the ice core is very likely but the reliability of resistivity values is, nevertheless, rather low.

In addition to the individual tomograms, a timelapse inversion was carried out for the data set (with the inversion result from 17 August 2006 used as a reference model for the later ERTM data). Resistivity changes were calculated for subsequent time steps and for the full 2-year period (August 2006-September 2008) and are plotted in Figure 6c. Blue and red colours stand for resistivity increases and decreases, respectively. For the time-lapse studies, separate DOI distributions were calculated for each tomogram. From these, we chose the maximum DOI distribution for each pair of tomograms as an upper bound for reliability of the calculated resistivity changes (referred to as DOI ${ }_{\max }$ in Figure 6c).

The time-lapse results show: (a) horizontally irregular changes within the active layer attributed to differences in water saturation, (b) a zone of more homogeneous changes at the transition to or within the uppermost part of the ice core, with a decrease of up to 75 per cent between summers 2006 and 2007, and (c) zones with large positive and negative changes (up to $40 \%$ ) in deeper parts of the profile and close to the rockglacier front. However, high DOI values in the zone of massive ice point to an increased risk of inversion artefacts or limited accuracy in resistivity values. Borehole temperatures that do not indicate large temperature variations in deeper parts of the rockglacier support the contention that resistivity changes in this zone are of low reliability.

According to relatively low DOI values in the upper parts of the time-lapse tomograms, the calculated resistivity changes in this zone are reliable results, and can be interpreted as true freeze/thaw processes (in agreement with the synthetic modelling results).

\section{Analysis of the Formal Model Resolution.}

Formal model resolution for the Murtèl data set (Figure 6d) is greatest in the active layer and the frontal part, and diminishes rapidly at the transition to the highly resistive ice core in all tomograms. Stummer et al. (2004) showed that electrical current concentration (resulting in larger formal model resolutions) occurs above and below resistive blocks or layers and gives a threshold of about 0.05 , below which model resolutions are considered to indicate only poorly resolved model regions. This value roughly corresponds to the red colour in Figure 6d (i.e. yellow and white colours stand for an unsatisfactory resolution). The conclusions for the Murtèl site are straightforward and confirm the findings of the synthetic modelling and DOI analyses: for rockglaciers with a highly resistive core of massive ice and corresponding strong resistivity contrast between the active layer and ice core, the resolution capacity of ERT data is very limited and can be described roughly as a function of conductivity. Consequently, resolution increases in zones with locally increased active-layer depth and lower resistivities at the surface of the ice core, as observed in both data sets from 2007 compared to 2006 and 2008 (Figure 6b). Also the less resistive vertical zone within the ice core is accentuated by slightly higher, but still poor, resolution. This implies that long-term permafrost degradation (associated with a resistivity decrease) would increase resolution in the respective model region, and should therefore be detectable by ERTM.

\section{DISCUSSION OF TIME-LAPSE ERTM RESULTS}

Using the results above, we can restrict the interpretation of time-lapse inversion results between summers 2006 and 2008 to reliable model regions (i.e. to the active layer and the top of the ice core). Apart from seasonal variations in the active layer, reflecting wetter or drier conditions, a significant decrease in resistivities can be observed along the whole survey line at the transition between the active layer and ice core in 2007, which is still present in September 2008 (Figure 6c, zone A). Hoelzle and Gruber (2008) reported that air temperatures in winter 2006-07 at nearby meteorological stations were the warmest ever recorded. Although snow cover thickness was the lowest since 1972, this prevented an effective cooling and caused significantly 
higher temperatures in the uppermost $15 \mathrm{~m}$ of the rockglacier in summer 2007 compared to 2006. The observed resistivity changes near the borehole position (indicated in Figure 6c) correspond to temperature differences of $0.2-0.8 \mathrm{~K}$ between depths of $3.8 \mathrm{~m}$ and $15 \mathrm{~m}$ (frozen) and even greater change in the uppermost 3 m (unfrozen) beween August 2006 and 2007. Note that the borehole is located in a zone with only minor resistivity changes, and that the more pronounced variations between $0-$ and $50-\mathrm{m}$, and $80-$ and $120-\mathrm{m}$ horizontal distance cannot be verified using the temperature data. We suggest that the exceptionally warm winter 2006-07 led to a sustained warming at the top of the ice core (zone A), with different magnitudes along the survey line and persisting for at least 2 years (summers 2007 and 2008). The negligible difference between August 2007 and September 2008 confirms that the impact of winter 2007 had not yet been compensated for thermally by late summer 2008 .

As active-layer thickness cannot grow over massive ice due to the absence of rock material from the ice itself (Haeberli and Vonder Mühll, 1996), the detection of permafrost degradation by ERTM would, strictly speaking, be possible only in terms of a resistivity decrease due to warming (not melting) of the permafrost. This is what we observe in zone A, where resistivity values of $>200 \mathrm{k} \Omega \mathrm{m}$ still indicate frozen conditions. Conversely, a resistivity decrease to less than $30 \mathrm{k} \Omega \mathrm{m}$, as observed in zone B in August 2007, points to unfrozen conditions. This in turn reflects a locally increased active-layer depth and indicates that the ice content must have been significantly lower in this part of the rockglacier (see above: otherwise thaw subsidence should have occurred rather than thickening of the active layer). The anomalous zone B amounts to 3-4-m thickness in the ERTM data, but, as discussed above, its true vertical extent is unknown. This local active-layer thickening is remarkable, since maximum active-layer depths (obtained from borehole temperatures) varied by only a few centimetres in the last 20 years (Vonder Mühll et al., 2007; Bauder et al., 2008), and by only $1 \mathrm{~cm}$ between 2006 and 2007 (note, that almost no resistivity change is visible at the borehole position). According to synthetic modelling (Figure 4, scenario (6)), we interpret the observed local activelayer thickening in summer 2007 to be a real feature, but the resolution capacity of its vertical extent is critical due to the large electrode spacing. In contrast to scenario (6), an interpretation according to scenario (5) is less probable as decreasing resistivity of the active layer due to local formation of a moist layer would be expected (cf. Figure 4), which was not observed.

We conclude from time-lapse analysis that ERTM revealed a spatially heterogeneous impact of the warm winter 2006-07 on the permafrost regime of Murtèl rockglacier, that is, in general, more severe than observed at the borehole position: the top of the ice layer shows a significant resistivity decrease, and locally (in a zone where less ice content is assumed) even melting of the ice (i.e. a thickening of the active layer) is indicated. In contrast to the overall resistivity decrease at the top of the ice core (zone A), local active-layer thickening (zone B) did not persist until summer 2008. ERTM will be continued in the future to evaluate whether the observed resistivity changes indicate longterm permafrost degradation.

\section{CONCLUSIONS}

Strong resistivity contrasts and high contact resistances make the acquisition, inversion and interpretation of ERT data from coarse blocky and ice-rich permafrost sites difficult. To assess changes during ERTM, it is essential to separate changes due to corresponding inversion artefacts from true temporal subsurface changes. Three appraisal methods were used to analyse an ERTM data set from Murtèl rockglacier. The application of these methods led step by step to the identification of unreliable model regions.

The strengths of the applied methods are:

- Forward-inverse cycles using synthetic models served to analyse structural information and potential temporal resistivity changes inferred from inversion results before the interpretation of timelapse data. Valuable insights into the potential to detect anticipated spatio-temporal resistivity changes are possible with this method.

- The DOI method provides information about model regions that are well constrained by the data and regions that are mainly influenced by the resistivity of the applied reference model. The maximum investigation depth and the reliability of the image in transition zones with gradational resistivity changes can both be estimated.

- The formal model resolution is roughly a function of electrical conductivity, and generally places low confidence in the inverted resistivities of highly resistive model regions.

From analysis of the applied appraisal techniques, it turned out that the information content of ERTM results could be refined by the combination of these methods, allowing a responsible evaluation of the information provided by time-lapse inversion. The general implications for the applicability of ERTM to coarse blocky and ice-rich permafrost sites are: 
- Without additional constraints in the inversion algorithm, temporal resistivity variations in zones with massive ice are most likely a function of a change in resistivity contrast, and therefore caused by the inversion process. Such features do not necessarily indicate true variations in the permafrost conditions!

- Temporal degradation phenomena in terms of longterm changes in active-layer thickness or rather melting of ground ice at the permafrost table are likely to be detectable by ERTM. The accuracy in determining the vertical extent of such features is, however, a function of electrode spacing and the DOI.

- Absolute resistivity values in zones of massive ground ice and in model regions with strong resistivity contrasts (e.g. between the active layer and massive ground ice) are strongly influenced by the inversion process and thus of very critical reliability. This has to be taken into account for ERT applications that relate absolute resistivity values to subsurface temperatures, or the ice origin of rockglaciers.

- As the inversion process is sensitive to strong resistivity contrasts, this problem can be minimised by conducting ERTM measurements (also) during winter when the active layer is frozen (if electrode coupling is sufficient). It is also recommended to extend survey lines into unfrozen surroundings at both ends of rockglaciers or other ice-rich landforms, to increase resolution near the lower boundary of the ice core.

- For Murtèl rockglacier all the above limitations prohibit detailed detection of processes within or below the ice core, but degradation phenomena from above, such as the observed local active-layer thickening and the pronounced resistivity decrease at the top of the ice core in 2007, can be identified.

Despite the limiting factors mentioned above, ERTM has great potential regarding the identification of the spatio-temporal heterogeneity of the anticipated climate-induced degradation of mountain permafrost and the relative quantification of ground-ice degradation.

\section{ACKNOWLEDGEMENTS}

We thank the students who helped with the data acquisition, especially Martin Baum and Sebastian Klein. We also express many thanks to Martin Hoelzle for making available the borehole data for Murtèl and for fruitful discussions of the ERTM results, and to the two reviewers for their constructive comments. The study was funded by the PERMOS network (BAFU,
Switzerland) and by the German Research Foundation (DFG, MA1308_22-1).

\section{REFERENCES}

Alumbaugh DL, Newman GA. 2000. Image appraisal for 2-D and 3-D electromagnetic inversion. Geophysics 65(5): 1455-1467. DOI:10.1190/1.1444834

Arenson L, Springman S. 2005. Triaxial constant stress and constant strain rate tests on ice-rich permafrost samples. Canadian Geotechnical Journal 42(2): 412430. DOI: $10.1139 / \mathrm{t} 04-111$

Arenson L, Hoelzle M, Springman S. 2002. Borehole deformation measurements and internal structure of some rock glaciers in Switzerland. Permafrost and Periglacial Processes 13(2): 117-135. DOI: 10.1002/ppp.414

Bauder A, Marty C, Noetzli J. 2008. Schnee, Gletscher und Permafrost 2005/06 und 2006/07. Die Alpen 9: 47-56.

Dahlin T, Loke MH. 1998. Resolution of 2D Wenner resistivity imaging as assessed by numerical modelling. Journal of Applied Geophysics 38(4): 237-249. DOI: $10.1016 /$ S0926-9851(97)00030-X

Delaloye R, Perruchoud E, Avian M, Kaufmann V, Bodin X, Hausmann H, Ikeda A, Kääb A, Kellerer-Pirklbauer A, Krainer K, Lambiel C, Mihajlovic D, Staub B, Roer I, Thibert E. 2008. Recent interannual variations of rock glacier creep in the European Alps. In Proceedings of the Ninth International Conference on Permafrost, Kane DL, Hinkel KM (eds). Institute of Northern Engineering, University of Alaska Fairbanks: Fairbanks, Alaska. Volume I: 343-348.

Edwards LS. 1977. Modified Pseudo-Section for Resistivity and IP. Geophysics 42(5): 1020-1036. DOI: 10.1190/1.1440762

Fortier R, LeBlanc AM, Allard M, Buteau S, Calmels F. 2008. Internal structure and conditions of permafrost mounds at Umiujaq in Nunavik, Canada, inferred from field investigation and electrical resistivity tomography. Canadian Journal of Earth Sciences 45(3): 367387. DOI: 10.1139/E08-004

Friedel S. 2003. Resolution, stability and efficiency of resistivity tomography estimated from a generalized inverse approach. Geophysical Journal International 153(2): 305-316. DOI: 10.1046/j.1365246X.2003.01890.x

Haeberli W, Vonder Mühll D. 1996. On the characteristics and possible origins of ice in rock glacier permafrost. Zeitschrift für Geomorphologie, N.F. Suppl. 1004: 43-57.

Haeberli W, Huder J, Keusen HR, Pika J, Röthlisberger H. 1988. Core drilling through rock glacier-permafrost. In Proceedings of the 5th International Conference on Permafrost, Senneset K (ed.). Tapir Publishers: Trondheim, Norway. Volume 2: 937-942. 
Haeberli W, Hoelzle M, Kääb A, Keller F, Vonder Mühll D, Wagner S. 1998. Ten years after drilling through the permafrost of the active rock glacier Murtèl, eastern Swiss Alps: answered questions and new perspectives. In Proceedings of the 7th International Conference on Permafrost, Lewkowicz AG, Allard M (eds). Yellowknife, Canada; 403-410.

Hauck C. 2002. Frozen ground monitoring using DC resistivity tomography. Geophysical Research Letters 29(21): 2016. DOI: 10.1029/2002GL014995

Hauck C, Kneisel C. 2008. Applied Ggeophysics in Periglacial Environments. Cambridge University Press: Cambridge; $240 \mathrm{pp}$.

Hauck C, Vonder Mühll D. 2003. Inversion and interpretation of two-dimensional geoelectrical measurements for detecting permafrost in mountainous regions. Permafrost and Periglacial Processes 14(4): 305-318. DOI: $10.1002 / p p p .462$

Hauck C, Vonder Mühll D, Maurer H. 2003. Using DC resistivity tomography to detect and characterize mountain permafrost. Geophysical Prospecting 51(4): 273-284. DOI: 10.1046/j.1365-2478.2003. 00375.x

Hilbich C, Hauck C, Hoelzle M, Scherler M, Schudel L, Völksch I, Vonder Mühll D, Mäusbacher R. 2008. Monitoring mountain permafrost evolution using electrical resistivity tomography: A 7-year study of seasonal, annual, and long-term variations at Schilthorn, Swiss Alps. Journal of Geophysical Research 113: F01S90. DOI: 10.1029/2007JF000799

Hoelzle M, Gruber S. 2008. Borehole and ground surface temperatures and their relationship to meteorological conditions in the Swiss Alps. In Proceedings of the Ninth International Conference on Permafrost, Kane DL, Hinkel KM (eds). Institute of Northern Engineering, University of Alaska Fairbanks: Fairbanks, Alaska. Volume I: 723-728.

Hoelzle M, Vonder Mühll D, Haeberli W. 2002. Thirty years of permafrost research in the CorvatschFurtschellas area, Eastern Swiss Alps: a review. Norwegian Journal of Geography 56: 137-145. DOI: 10.1080/002919502760056468

Ikeda A, Matsuoka N. 2006. Pebbly versus bouldery rock glaciers: Morphology, structure and processes. Geomorphology 73(3-4): 279-296. DOI: 10.1016/ j.geomorph.2005.07.015

Ishikawa M, Watanabe T, Nakamura N. 2001. Genetic differences of rock glaciers and the discontinuous mountain permafrost zone in Kanchanjunga Himal, Eastern Nepal. Permafrost and Periglacial Processes 12(2): 243-253. DOI: 10.1002/ppp.394

Kääb A, Gudmundsson GH, Hoelzle M. 1998. Surface deformation of creeping mountain permafrost. Photogrammetric investigations on rock glacier Murtél, Swiss Alps. In Proceedings of the 7th International Conference on Permafrost, Lewkowicz AG, Allard M (eds). Yellowknife, Canada; 531-537.

Kääb A, Frauenfelder R, Roer I. 2007. On the response of rockglacier creep to surface temperature increase.
Global and Planetary Change 56(1-2): 172-187. DOI: 10.1016/j.gloplacha.2006.07.005

Kneisel C, Hauck C. 2008. Electrical methods. In Applied Geophysics in Periglacial Environments, Hauck C, Kneisel C (eds). Cambridge University Press: Cambridge; 3-27.

Kneisel C, Kääb A. 2007. Mountain permafrost dynamics within a recently exposed glacier forefield inferred by a combined geomorphological, geophysical and photogrammetrical approach. Earth Surface Processes and Landforms 32(12): 1797-1810. DOI: 10.1002/esp.1488

Loke MH. 1999. Time lapse resistivity imaging inversion. In Proceedings of the $5^{\text {th }}$ Meeting of the EEGS European Section, Em1, Budapest, Hungary (abstract available at www.geoelectrical.com/downloads.php) [3 June 2009].

Loke MH. 2002. RES2DMOD ver. 3.01: Rapid 2D resistivity forward modelling using the finite-difference and finite-element methods. (www.geoelectrical. com/downloads.php) [3 June 2009].

Loke MH, Barker RD. 1996. Rapid least-squares inversion of apparent resistivity pseudosections by a quasiNewton method. Geophysical Prospecting 44(1): 131152. DOI: 10.1111/j.1365-2478. 1996.tb00142.x

Loke MH, Dahlin T. 2002. A comparison of GaussNewton and quasi-Newton methods in resistivity imaging inversion. Journal of Applied Geophysics 49: 149-162. DOI: 10.1016/S0926-9851(01)00106-9

Loke MH, Acworth I, Dahlin T. 2003. A comparison of smooth and blocky inversion methods in 2D electrical imaging surveys. Exploration Geophysics 34(3): 182187. DOI: $10.1071 / \mathrm{EG} 03182$

Marescot L, Loke MH, Chapellier D, Delaloye R, Lambiel C, Reynard E. 2003. Assessing reliability of 2D resistivity imaging in mountain permafrost studies using the depth of investigation index method. Near Surface Geophysics 1(2): 57-67.

Maurer H, Hauck C. 2007. Geophysical imaging of alpine rock glaciers. Journal of Glaciology 53(180): 110-120. DOI: 10.3189/172756507781833893

Menke W. 1984. Geophysical data analysis: Discrete inverse theory. Academic Press, Inc.: Orlando; 260 pp.

Olayinka AI, Yaramanci U. 2000. Assessment of the reliability of 2D inversion of apparent resistivity data. Geophysical Prospecting 48(2): 293-316.

Oldenburg DW, Li YG. 1999. Estimating depth of investigation in de resistivity and IP surveys. Geophysics 64(2): 403-416. DOI: 10.1190/1.1444545

Press WH, Teukolsky SA, Vetterling WT, Flannery BP. 1992. Numerical recipies in C. Cambridge University Press: Cambridge; 994 pp.

Rings J, Scheuermann A, Preko K, Hauck C. 2008. Soil water content monitoring on a dike model using electrical resistivity tomography. Near Surface Geophysics 6: $123-132$.

Roer I, Kääb A, Dikau R. 2005. Rockglacier acceleration in the Turtmann valley (Swiss Alps): Probable controls. Norwegian Journal of Geography 59: 157-163. DOI: $10.1080 / 00291950510020655$ 
Routh PS, Miller CR. 2006. Image interpretation using appraisal analysis. SAGEEP Proceedings, 1812-1820.

Scales JA, Snieder R. 2000. The anatomy of inverse problems. Geophysics 65(6): 1708-1710.

Schön JH. 2004. Physical properties of rocks: Fundamentals and principles of petrophysics. Elsevier: Amsterdam; 600 pp.

Stummer P, Maurer H, Green AG. 2004. Experimental design: Electrical resistivity data sets that provide optimum subsurface information. Geophysics 69(1): 120-139. DOI: 10.1190/1.1649381

Vonder Mühll D, Holub P. 1992. Borehole logging in Alpine permafrost, Upper Engadine, Swiss Alps. Permafrost and Periglacial Processes 3(2): 125-132. DOI: $10.1002 /$ ppp.3430030209
Vonder Mühll DS, Klingelé EE. 1994. Gravimetrical Investigation of Ice-Rich Permafrost within the Rock Glacier Murtèl-Corvatsch (Upper Engadin, Swiss Alps). Permafrost and Periglacial Processes 5(1): 13-24. DOI: 10.1002/ppp.3430050103

Vonder Mühll DS, Hauck C, Lehmann F. 2000. Verification of geophysical models in Alpine permafrost using borehole information. Annals of Glaciology 31: 300306. DOI: 10.3189/172756400781820057

Vonder Mühll D, Noetzli J, Roer I, Makowski K, Delaloye R. 2007. Permafrost in Switzerland 2002/2003 and 2003/2004. Glaciological Report (Permafrost) No. 4/5 of the Cryospheric Commission (CC) of the Swiss Academy of Sciences (SCNAT) and the Department of Geography, University of Zurich, 107 pp. 